Journal of Business \& Management (COES\&RJ-JBM)

ISSN (E): 2306-7179 ISSN (P): 2306-8043

Publisher: Centre of Excellence for Scientific \& Research Journalism, COES\&RJ LLC

Online Publication Date \& Issue: 1st October 2017, Vol.5, No.4, October 2017

https://doi.org/10.25255/jbm.2017.5.4.153.166

\title{
The efficiency of human resources in \\ Islamic Banks
}

Mrs. Dr. Boufatah Keltouma Yasser

Faculty of Economics and Management

University of Tlemcen, Algeria

\begin{abstract}
:
The most important thing that distinguishes the Islamic religion from other religions is that it was not only concerned with the enlightenment of man with the doctrinal origins of unification and the organization of human relations with his Lord, but also with the individual's insight into the affairs of his life and what he organizes to achieve happiness in this life and the afterlife, Whether the Holy Qur'an, the Noble Sunnah or the behavior of the Caliphs in the management of the affairs of the Islamic State can be deduced that the latter had a head start in the use of many principles and concepts of sound management, which could not be reached by western management thought in recent years of this The Century after about fourteen centuries of the application of Islamic management to them, perhaps this is what made the scientists of the West themselves, such as Claude George in his book published in 1968 in the United States of America praises some of the pioneers of administrative thought Kalghazali, Al-Farabi and Ibn Khaldun etc.
\end{abstract}

Keywords

Human resource, Islamic banks, efficiency

\section{Citation:}

Yasser, Boufatah Keltouma (2017), The efficiency of human resources in Islamic Banks; Journal of Business \& Management (COES\&RJ-JBM)Vol.5,No.4,pp.153-166, https://doi.org/10.25255/jbm.2017.5.4.153.166. 


\section{السيدةالدكتورة طفياني المزدادة بوفاتح كلتومة

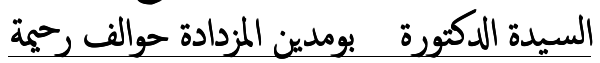 كلية العلوم الاقتصادية والتسبيي جامعة تلمسان الجزائر الملخص \\ "كفاءة الموارد البشرية في المصارف الاسلامية"}

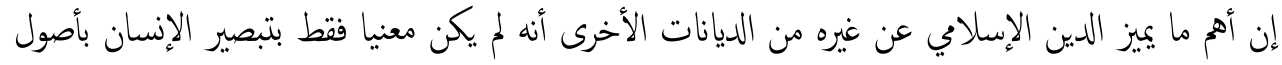

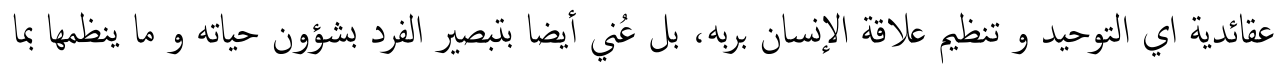

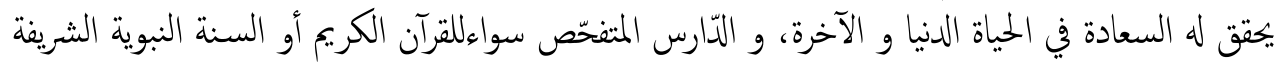

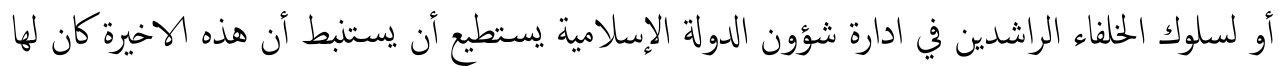

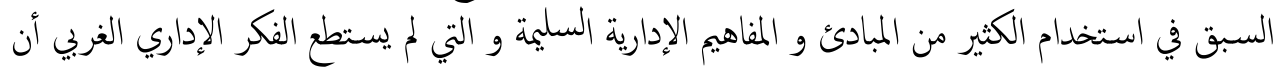

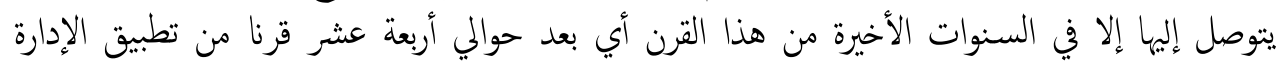

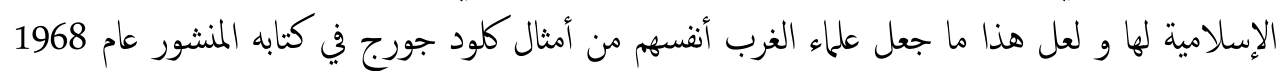

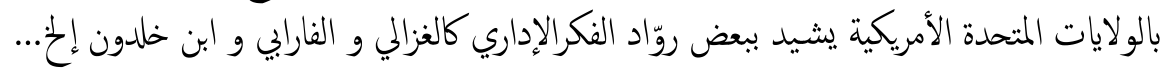

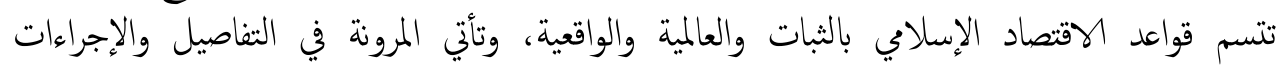

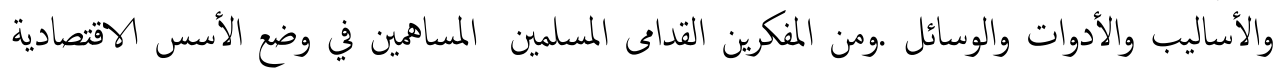

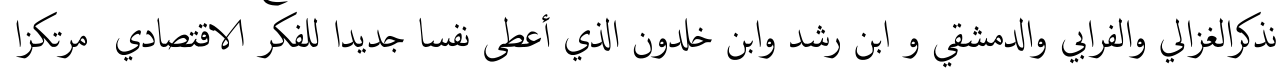

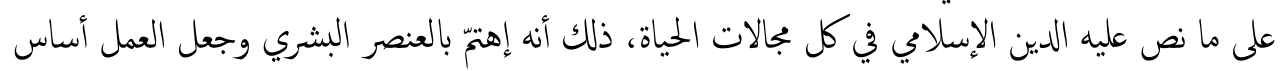

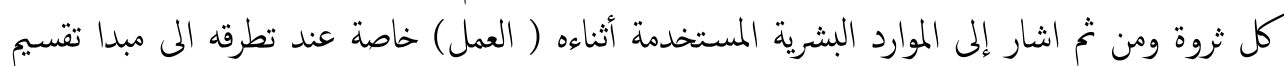

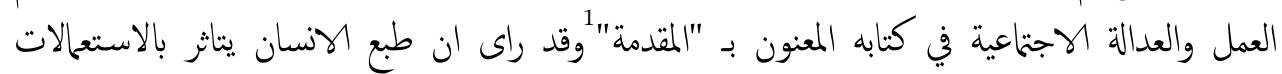

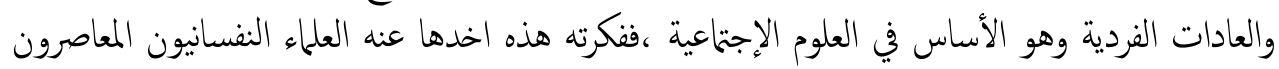
مثل غوستاف ليبون (1841-1931). ومن ثخ كان موضوعنا الخختارمتعلق بالعنصر البشري في المصارف الهسلامية مرتكزين على الكفاءة العملية

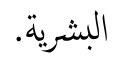
نتيجة الانقتاح على الاقتصاد العالمي والاصلاحات الهيكلية في النظام المالي وتحريرحركة رؤوس الاموال و

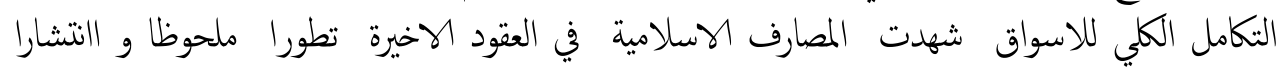

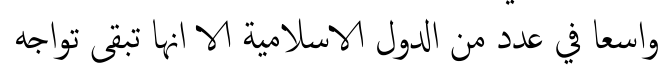

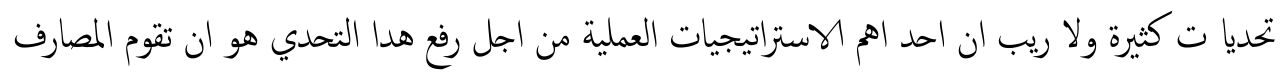

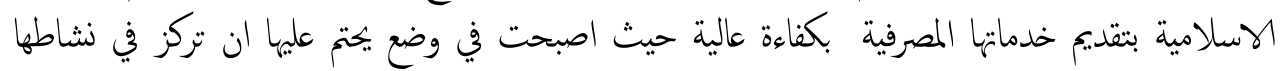

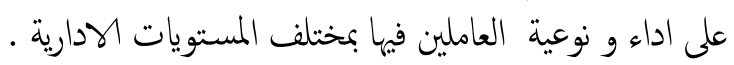


بدالتطبيق العملي لفكرة انشاء بنوك اسلامية تنتقل من المشرق العربي حيث كانت بدايتها المى المغرب

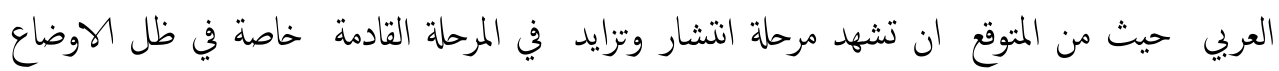

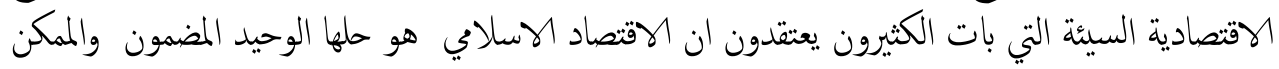

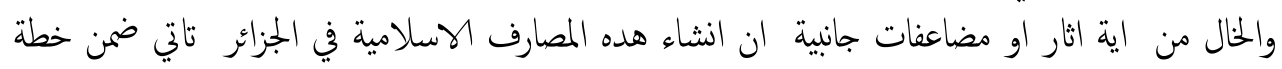

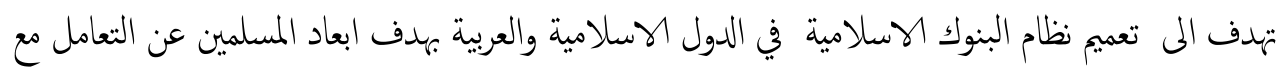

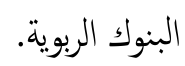

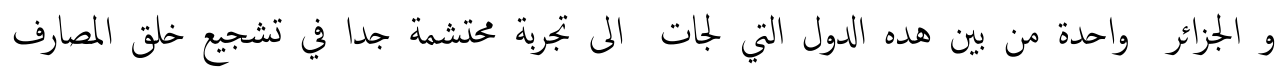

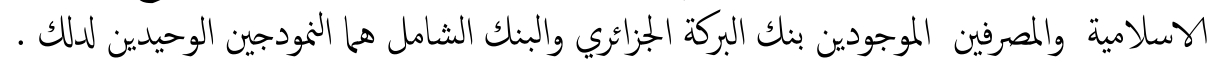

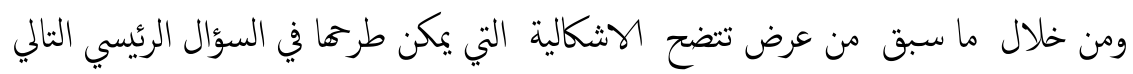

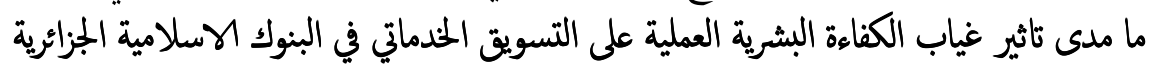

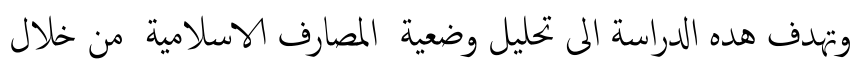

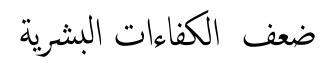
عدم ارتكاز البنوك الاسلامية على اداء و نوعية العاملين بمختلف المستويات الماتل المارية

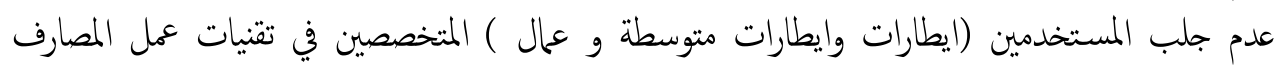
الهسلامية المبل

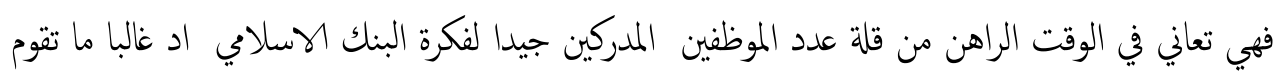

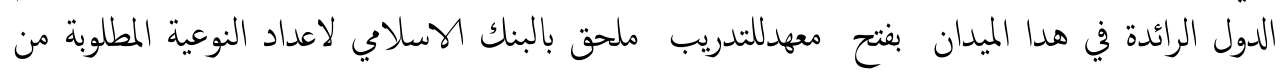

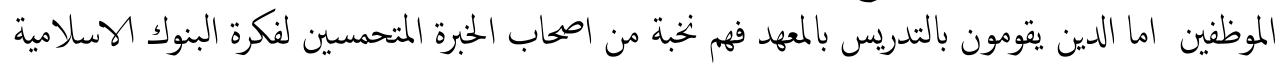

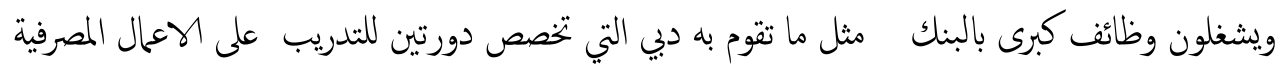

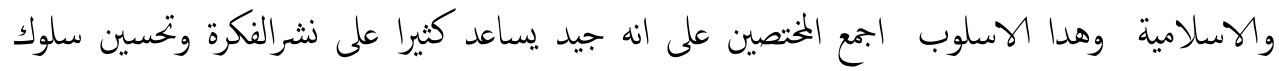

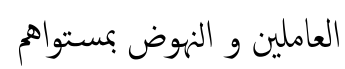

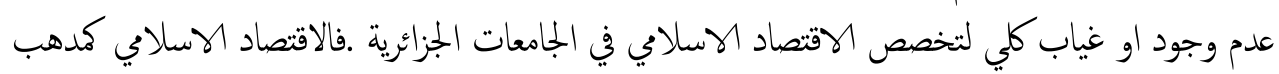

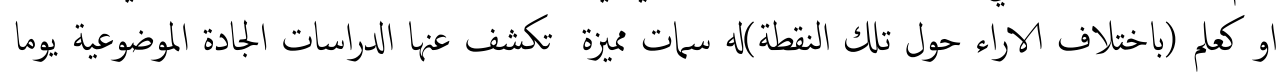

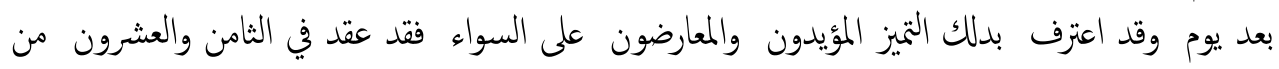

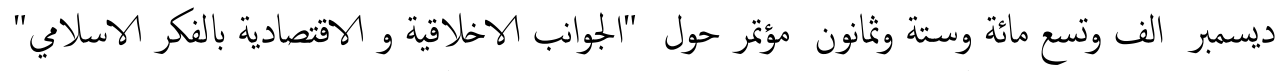

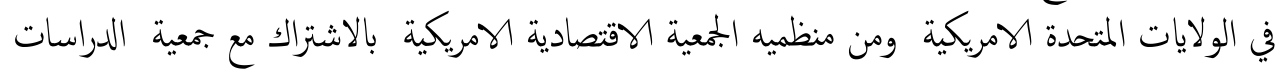

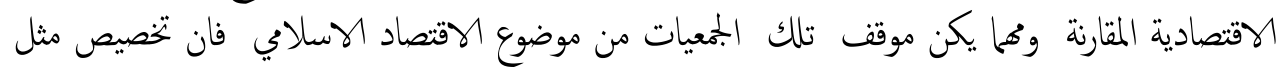

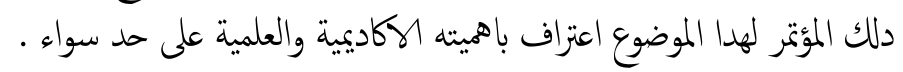

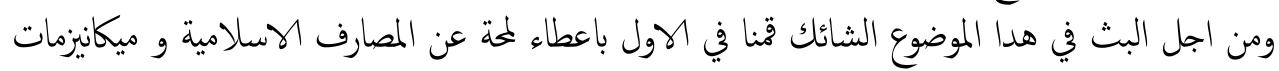

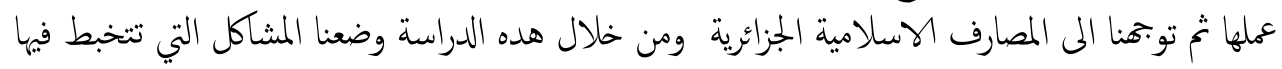


هده البنوك واخيرا قُنا بضبط الاشكلية من خلال وضع الكفاءات الجزائرية في هده المصارف تحت الضوء

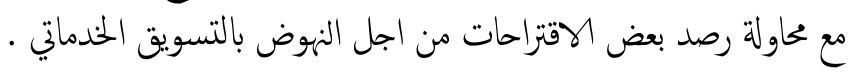

مقدمة

الإبلامية تسهيل المعاملات و التبادل و تيسير عملية الإنتاج وتعزيز طاقة رأس المال في إطار الثريعة ;وتسايرا مع متطلبات العصر، أصبحت المصارف الإسلامية ضرورة وحتمية اقتصادية لكل مجتع إسلاي

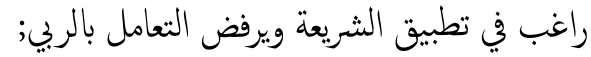

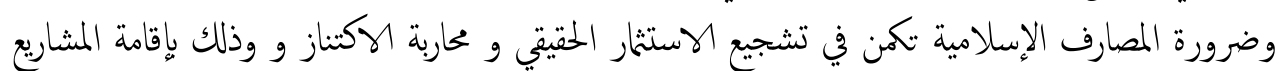

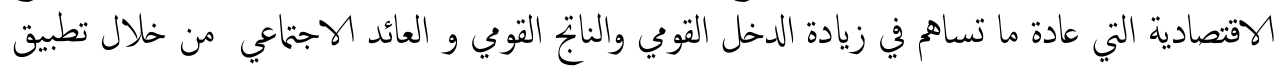

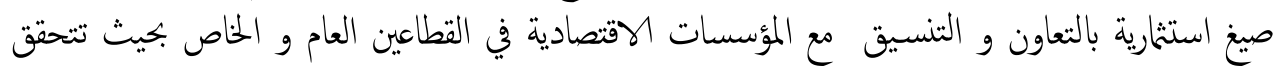

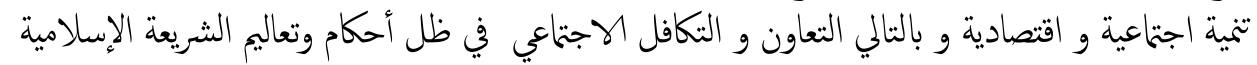

لمحةعامة عن المصارف الكسلامية وميكانيزمات عملها:

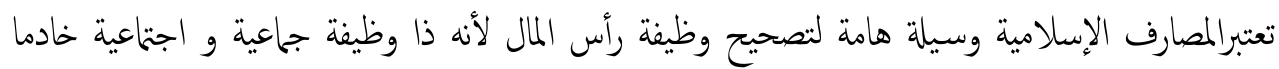

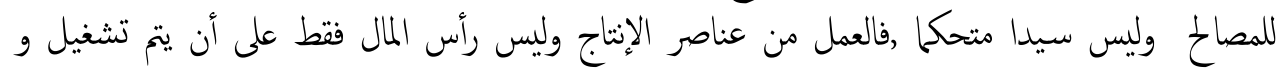

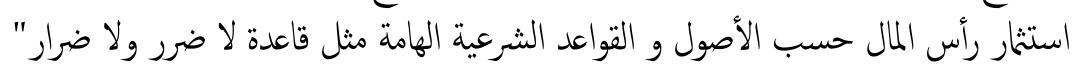

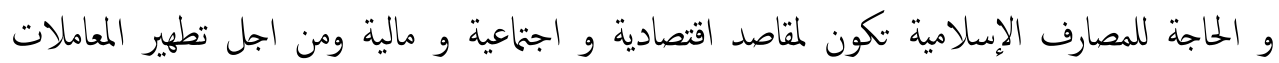
المصرفية من الربا لذلك أصبحت متواجدة في كافة بقاع الأعام العالم.

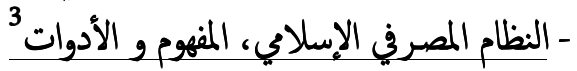

- مفهوم النظام المصرفي الإسلاي و نثأته :

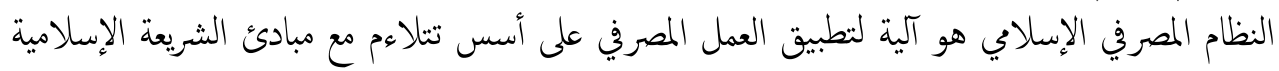

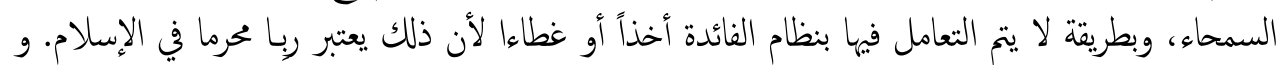

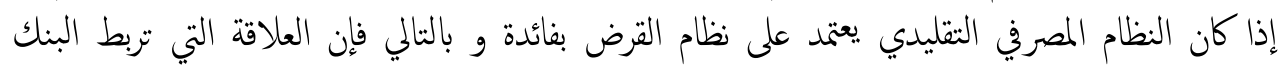

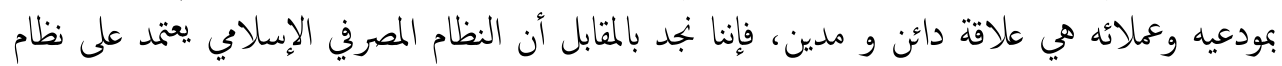

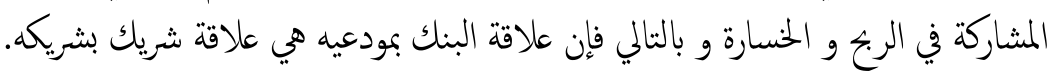

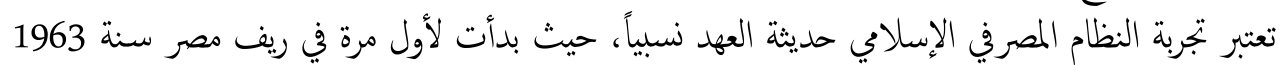

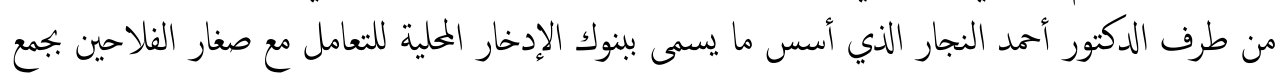

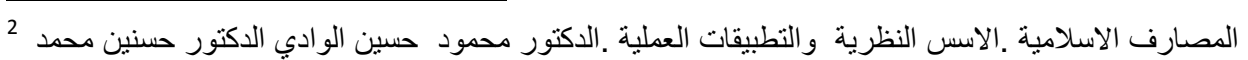

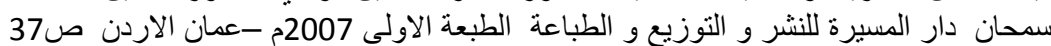

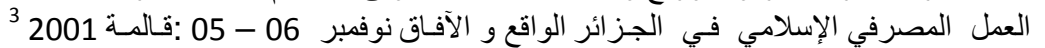

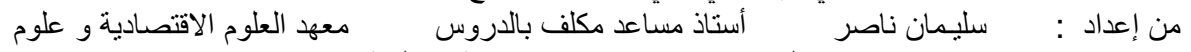

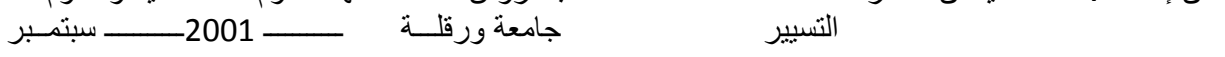




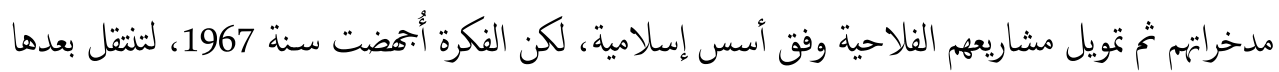

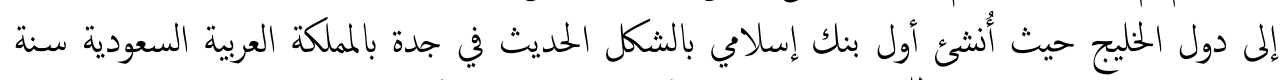

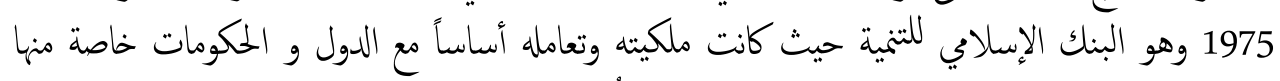

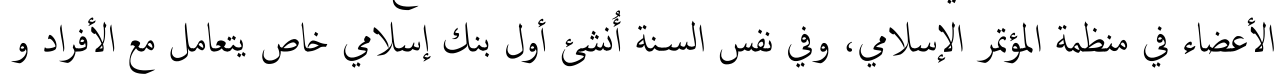
هو بنك دبي الإسلاي. - أدوات النظام المصرفي الإسلاي :

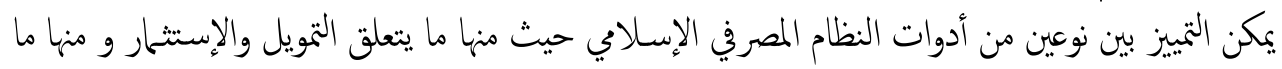
يتعلق بالخدمات المصرفية.

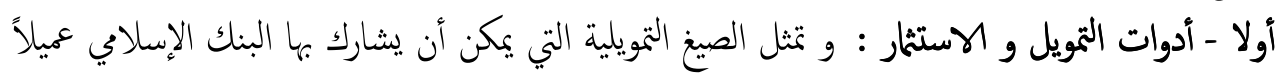

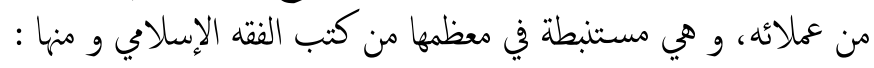

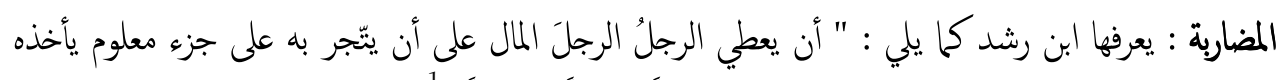

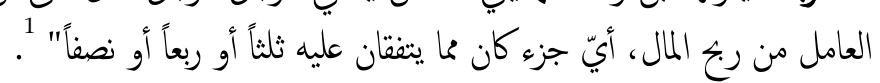

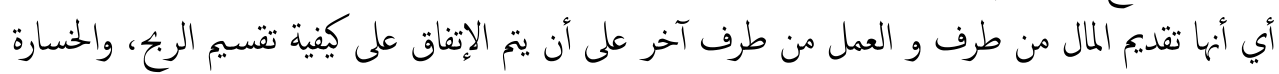

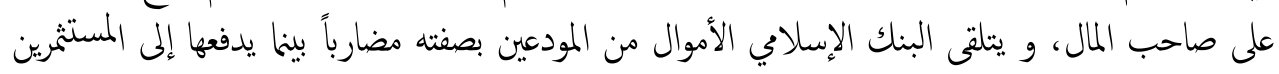
بصنته رباً للمال.

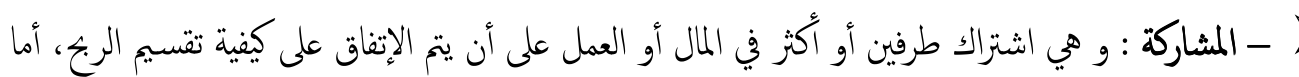

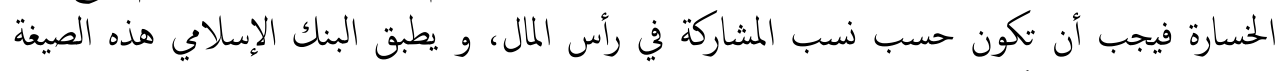
بالدخول بأمواله شريكاً مع طرف أو مجموعة أطراف في تمويل المشاريع مع اشتراكه في إدارتها ومتابعتها.

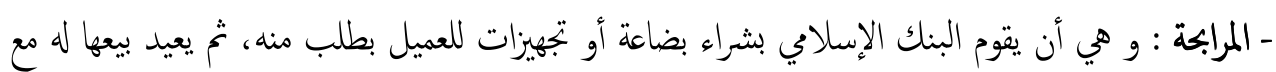

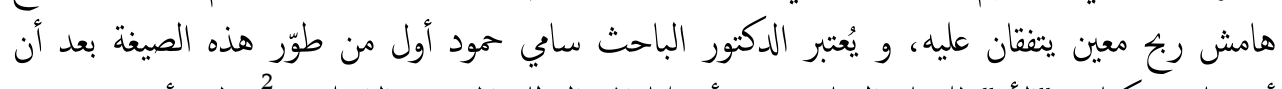

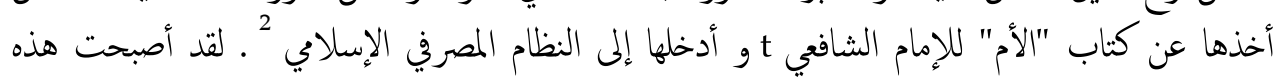

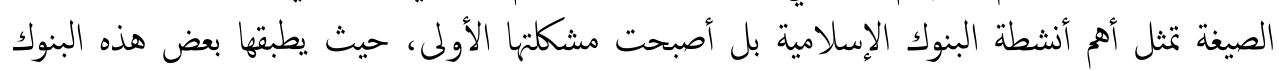

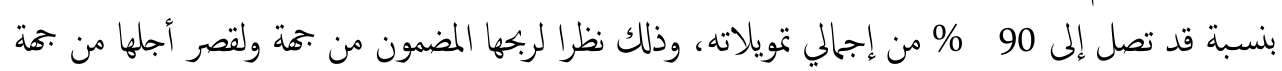
أخرى.

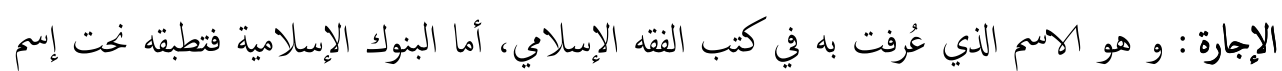

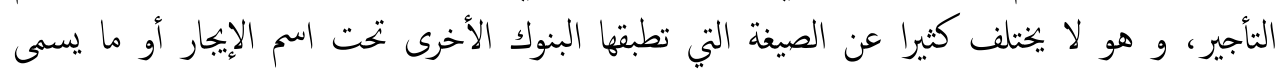

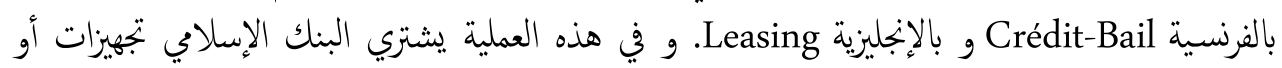

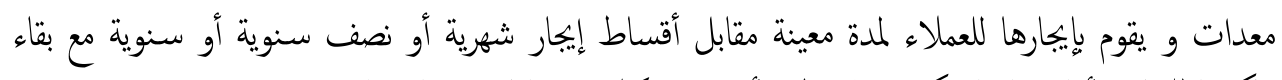
ملكيتها للبنك، أما صيانتها فتكون على المستأجر مع إمكانية بيعها لل في نهاية ألمانية المدة. 
-الإستصناع : و هو أن يطلب العميل من البنك الإسلاي صناعة شيء معين غير متوفر في السوق،

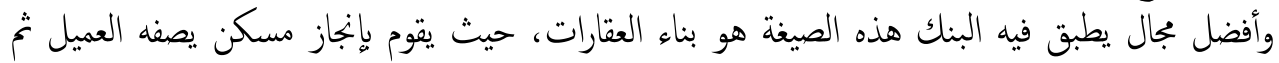
يبيعه إياه بالتقسيط عادة مقابل ضمانات تدفع مسبقاً.

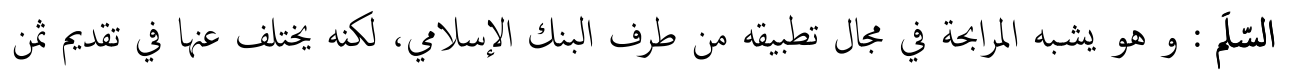

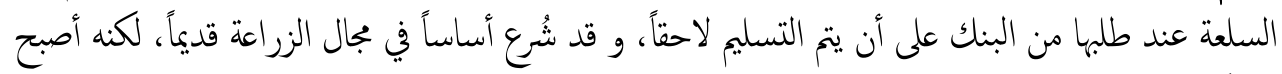

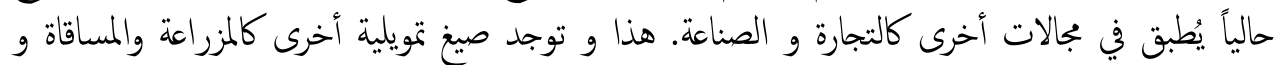

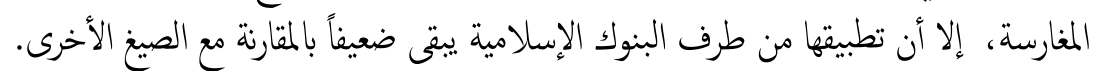

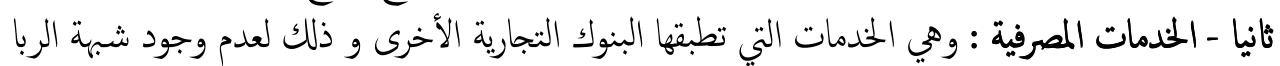

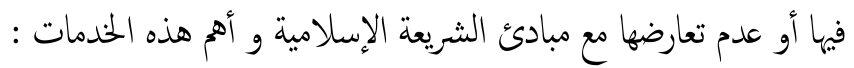

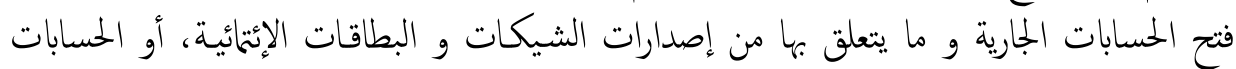

$$
\begin{aligned}
& \text { الادخارية والاستثمرية. } \\
& \text { تحصيل الأوراق التجارية . } \\
& \text { التحويلات الداخلية و الخارجية . }
\end{aligned}
$$

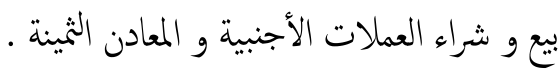

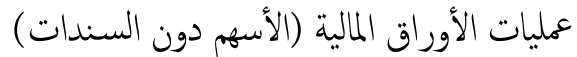

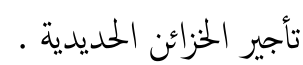

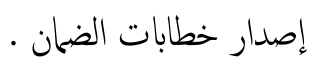

$$
\begin{aligned}
& \text { فتح الاعتمادات المستندية . } \\
& \text { تقديم الاستشارات و دراسات الجدوى الاقتصادية ...إلخ. }
\end{aligned}
$$

- - مثاة البنوك الاسلامية وتطورها: -

ان المحاولات الجادة في العصرالحديث للتخلص من الحماه المعاملات المصرفية الربوية واقامة مصارف تقوم بالخدمات

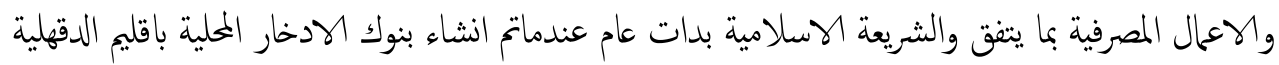

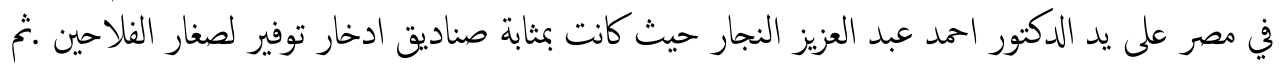

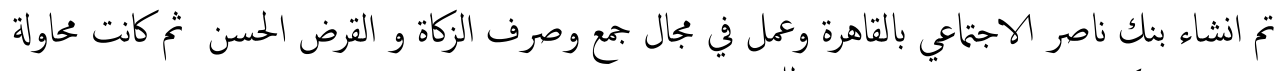

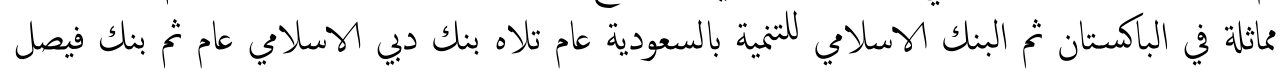

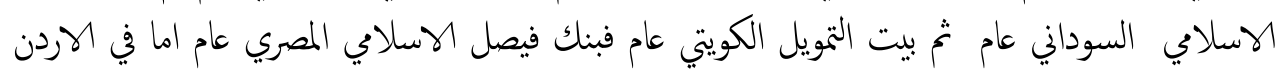

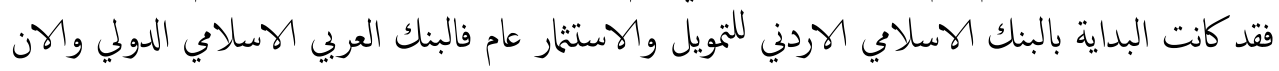

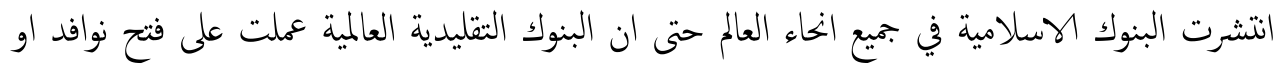

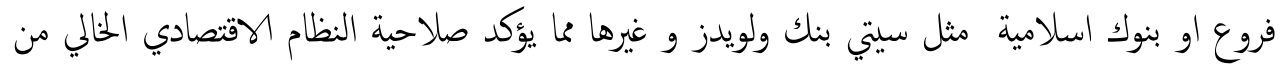




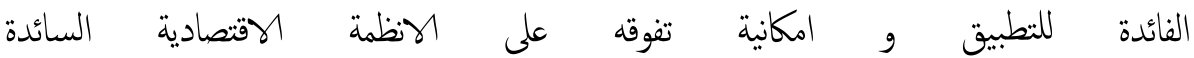

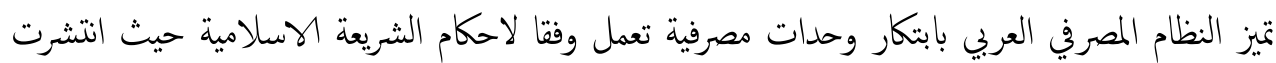

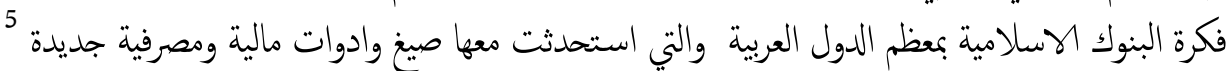

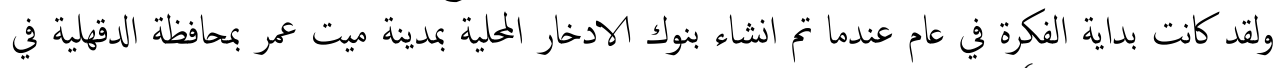
جمهورية مصرالعربية - - خصائص المصارف الهسلامية:

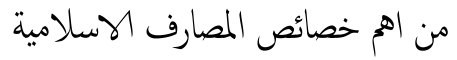
ل الخضوع للمبادئ والقيم الاسلامية

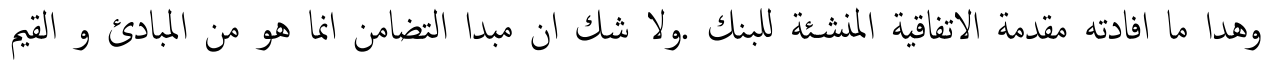

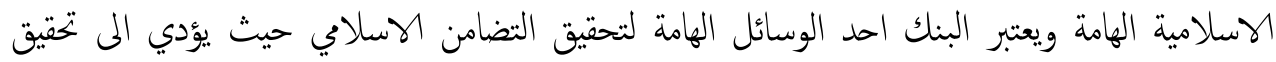

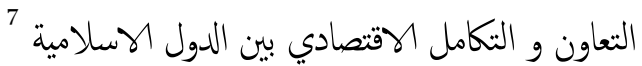
وقد دابت الدول العربية على بدل جهود كبيرة لتطوير وتحديث الصناعة المصرفية العربية لمواكبة التطورات

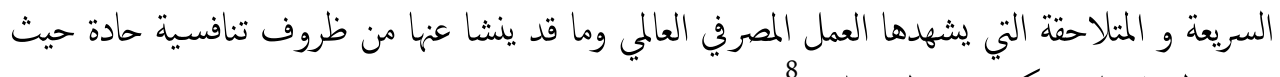

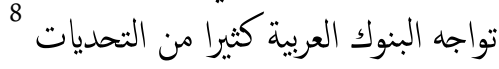
تسيير الافراد في المصارف الإسلامية:

\section{- مور العاملين في تطوير مسيرة البنوك الاسلامية؛}

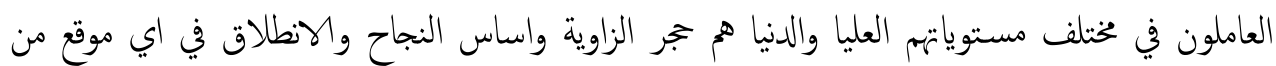

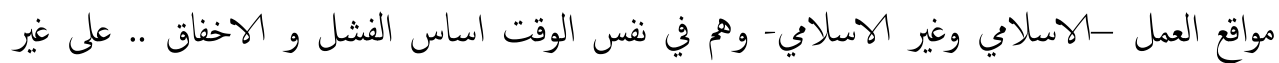

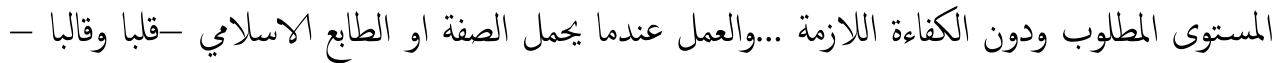

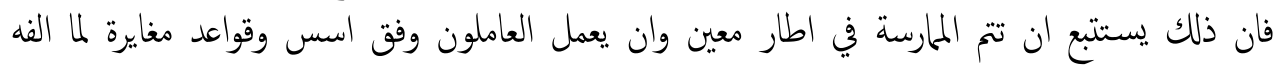

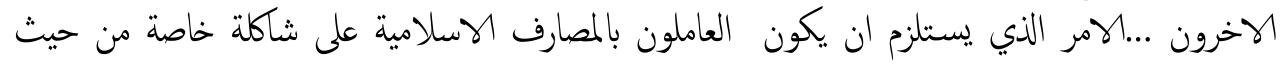

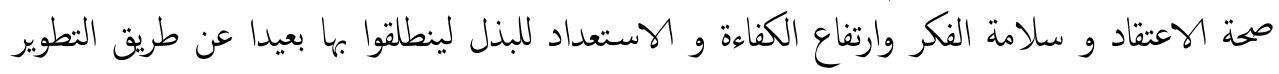

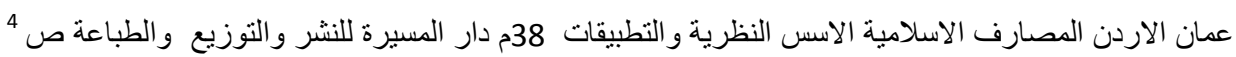

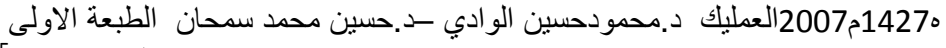

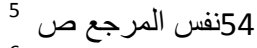

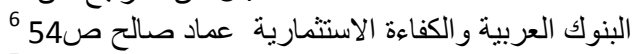

2007البنوك الاسلامية الدولية وعقودها مع اشارة خاصة لنظام التاجير التمويلي د. هشام خالد دار الفكر الجامية 7 36 الاسكندرية صية البية

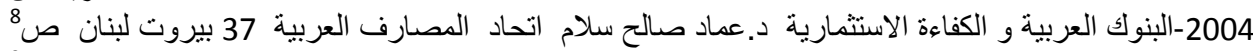

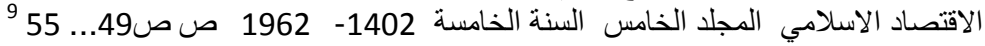


والتمكين ...وحول هؤلاء العاملين وطريقة اختيار هم وترشيحهم للوظائف ...وكيفية امتزابحم بمؤسساتهم اللاتي

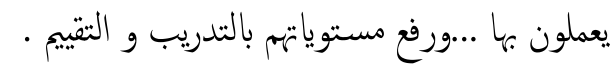

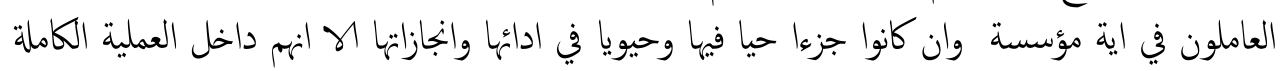

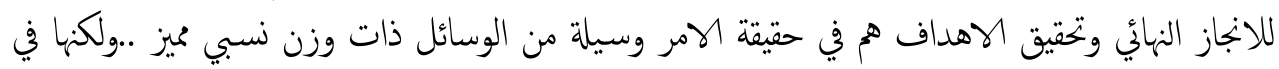

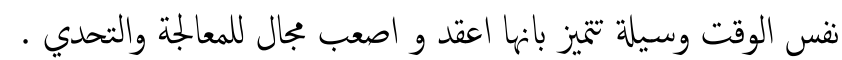

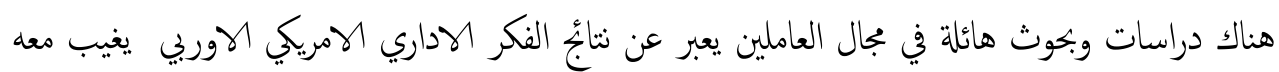

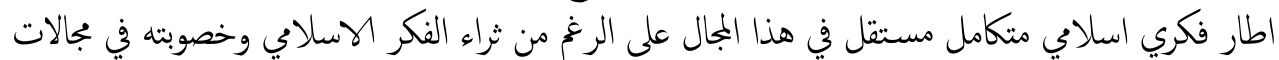
العلوم الانسانية.

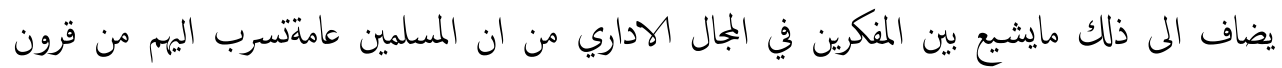

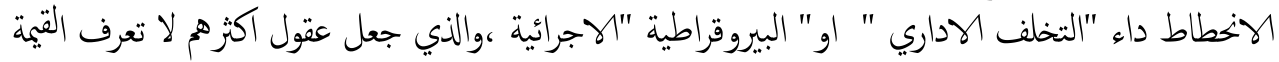

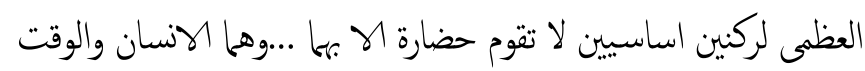

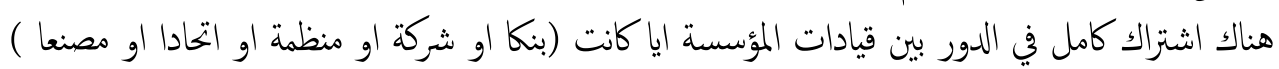

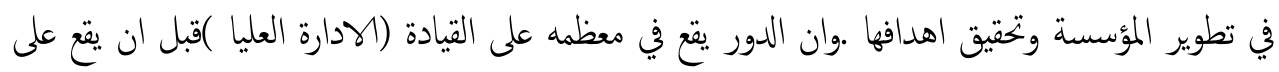

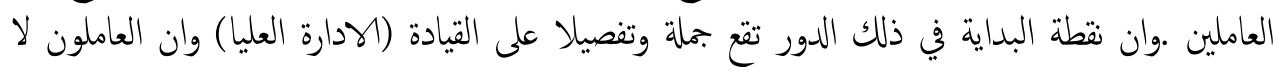

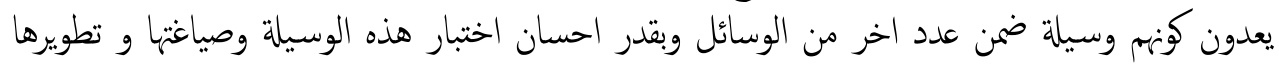

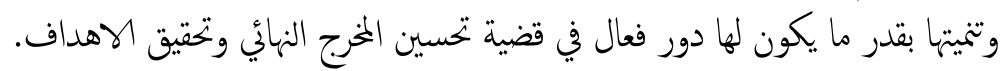
-

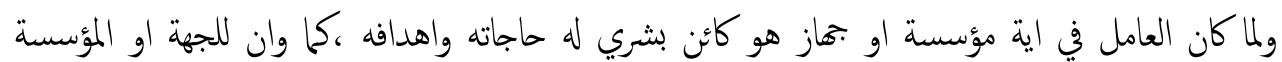

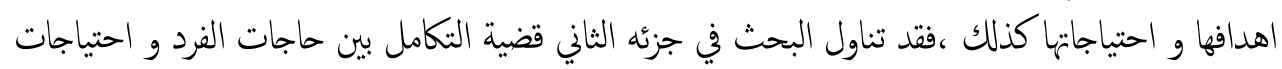

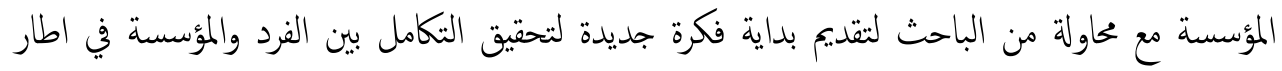

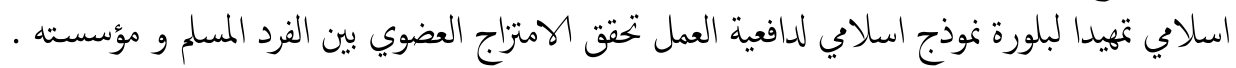

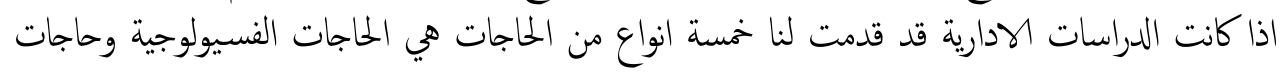

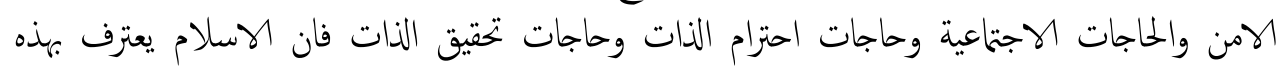

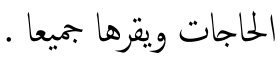

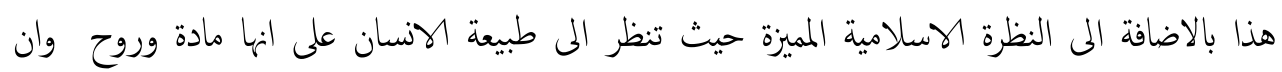

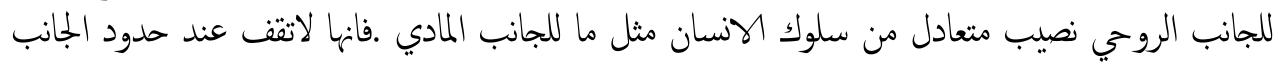

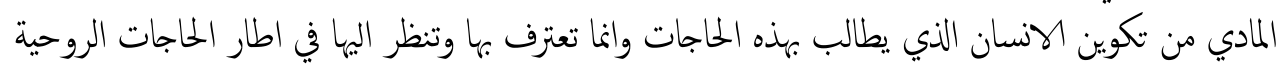
وتحت ضبطها وتوجيها وسيطرتها .

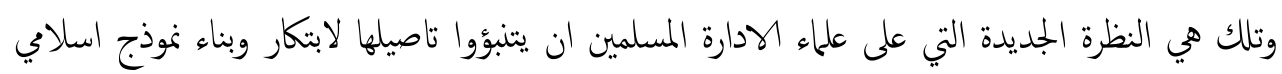

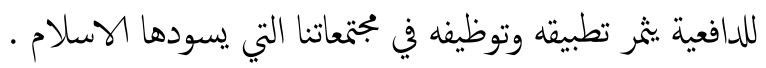




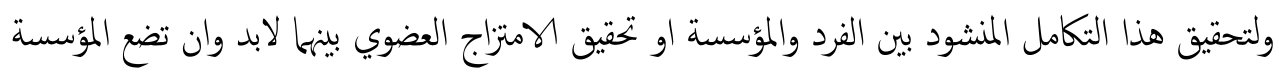

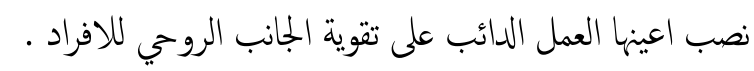

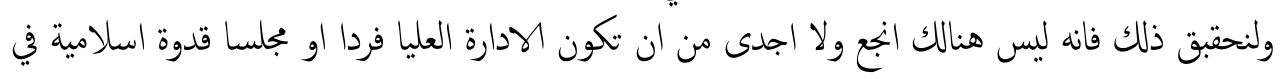
كل ماتاتيه اوتدعه من تصرفات. - تقييم الاداء والثدريب في المؤسسات المالية:

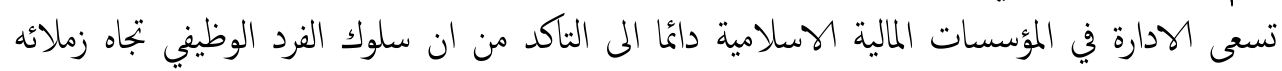

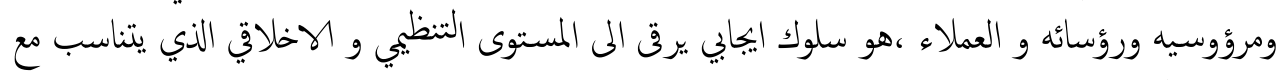

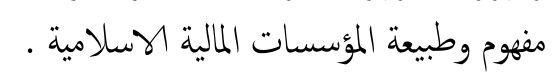

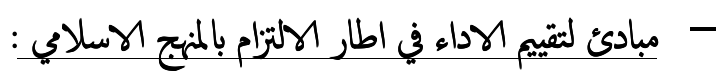

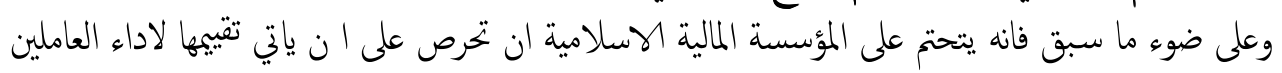

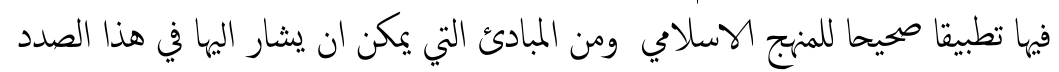

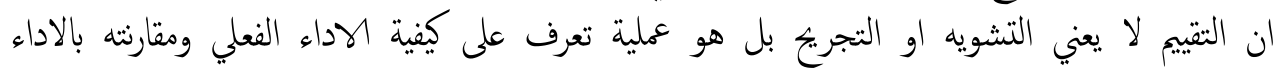

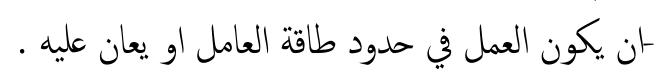

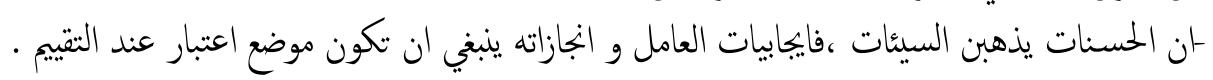

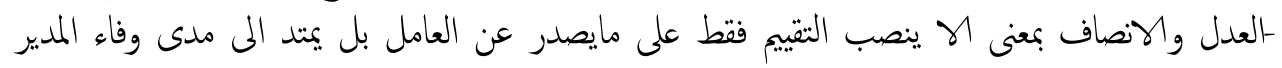
بواجباته حياله .

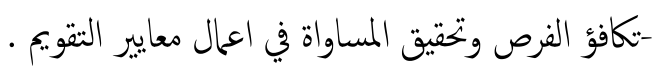

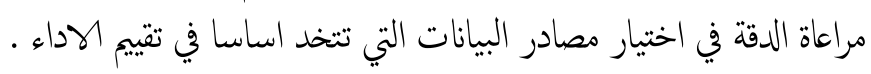

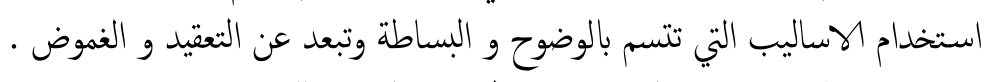

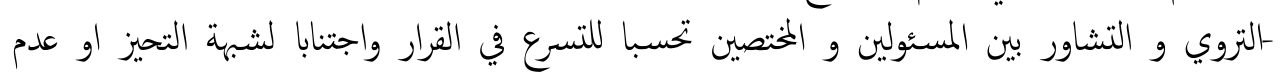
الموضوعية .

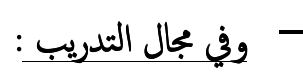

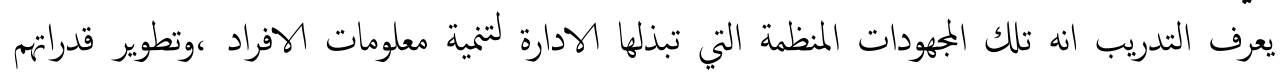

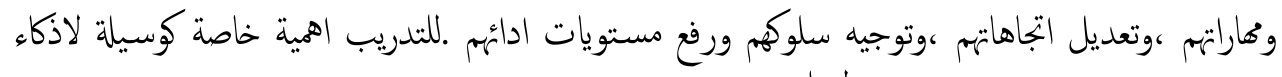

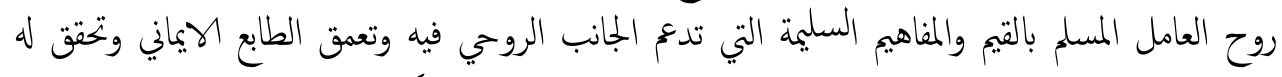

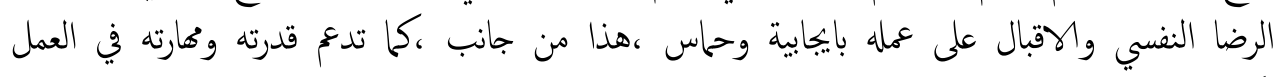

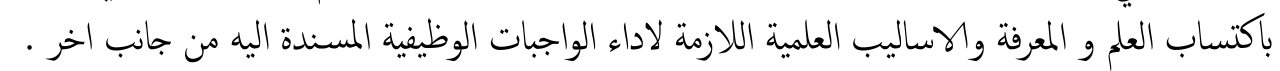

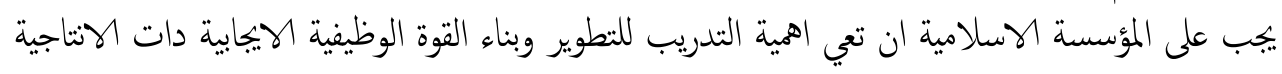

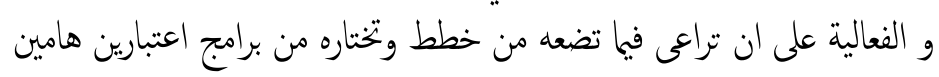


ان تتوافق هذه الخطط وتلك البرامج مع الاطار الاسلامي الشامل نموذج الدافعية الاسلامية الذي سلفت

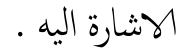
وان تنقى تلك البرامج من اية شوائب قد تكون علقت بها من ممارسات لا تنتي الى الفكر والعقيدة

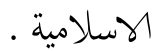
- توفر الادارة القدوة هو السبيل: القضية في تطوير عمل ومسيرة البنوك الاسلامية ليست قضية الموظف بشكل الحمل مطلق ، وانما هي اولا واخيرا

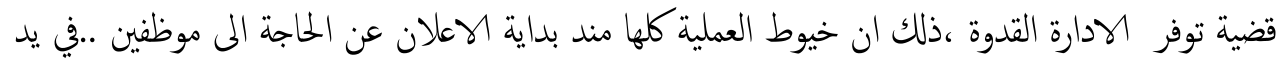

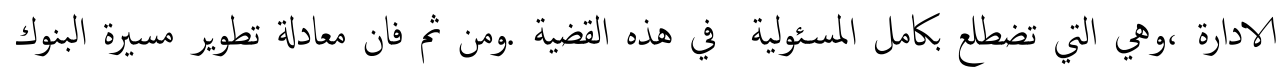
الاسلامية بككن ان تتمثل اطرافها في الصياغة التالية

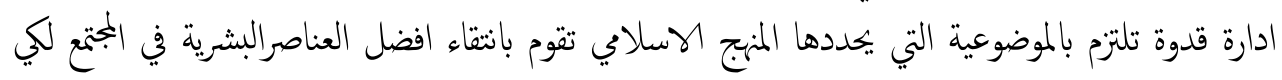

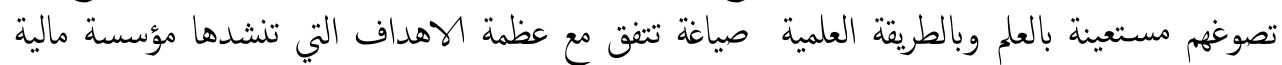

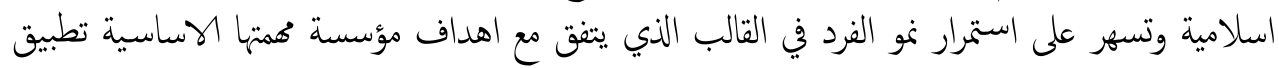

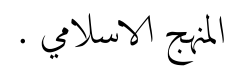
وفي ضوء معايشتنا للواقع المصرفي الاسلامي وادراكه لتاكيد الاسلام على ضرورة واهمية استخدام العلم

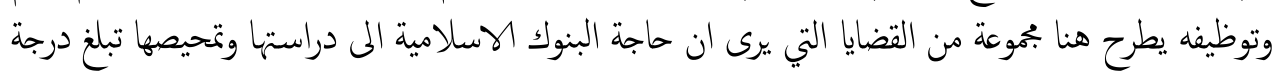

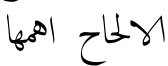
تحليل العمل في المؤسسات المالية الاسلامية حيث لا يوجد حتى الان تحليل علمي مكتمل للاعمال الخختلفة

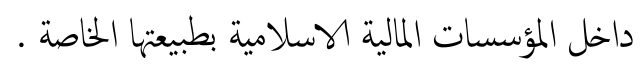

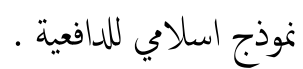

الاستعدادات و القدرات الخاصة و التجاهات اللازمة للنجاح في العمل في المؤسسات المالية الاسلامية .

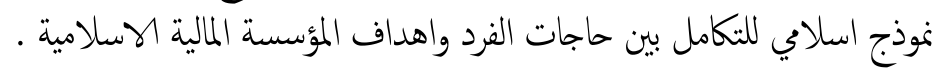

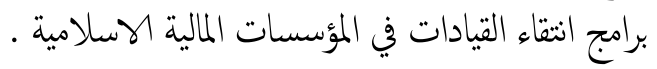

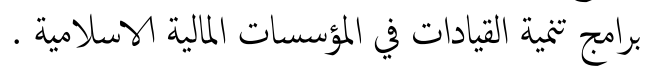

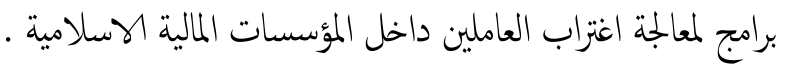

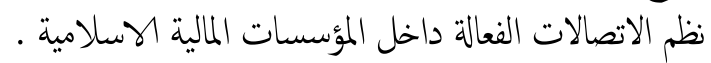

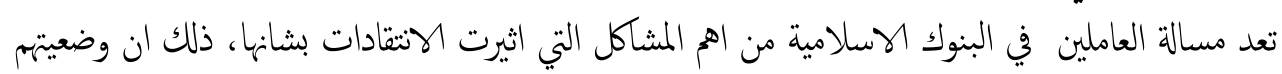

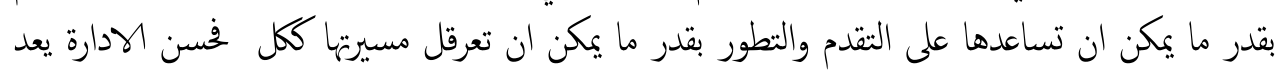

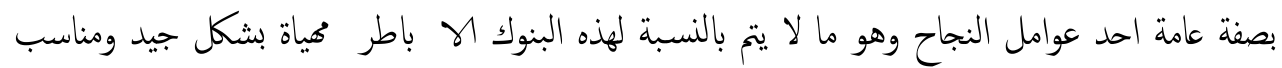

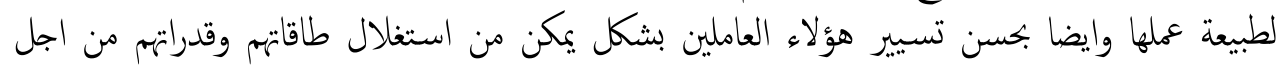

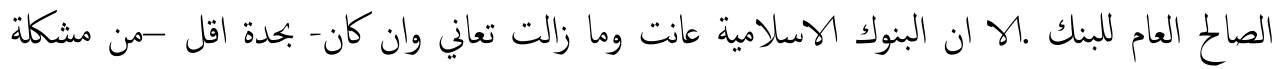


العاملين بها وانتقدت من حيث كنها لا تتوفر على الاطر البشرية المؤهلة علميا و عنيا لتسييرها ولندبير

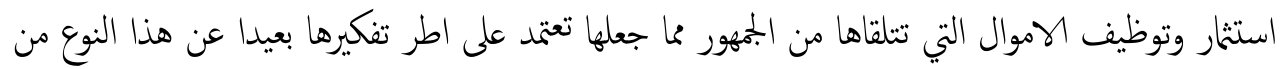

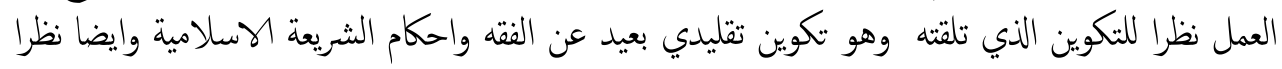

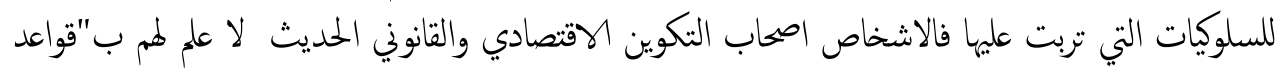

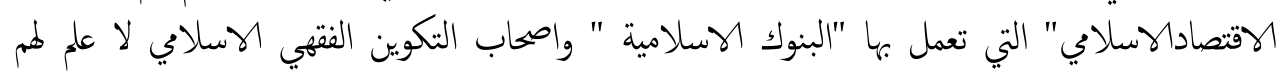

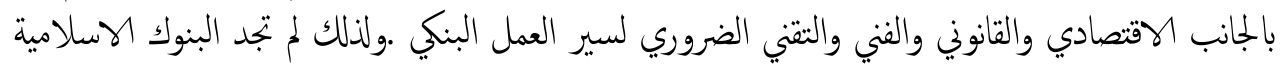

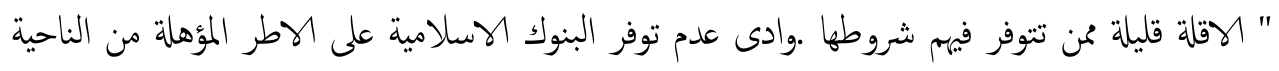

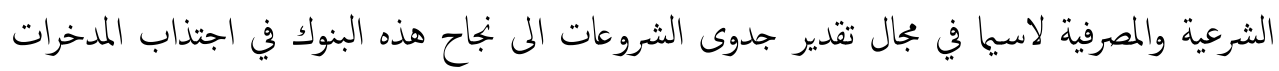

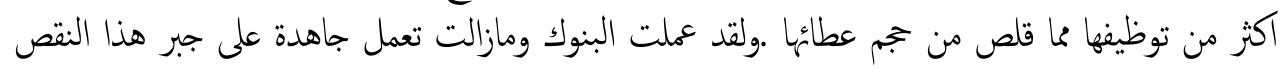

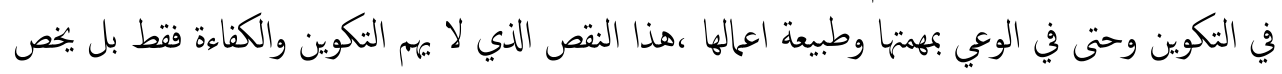

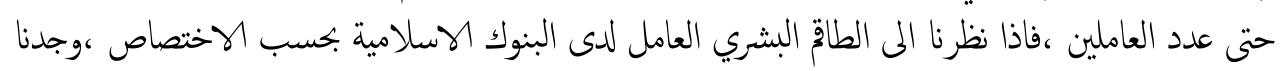

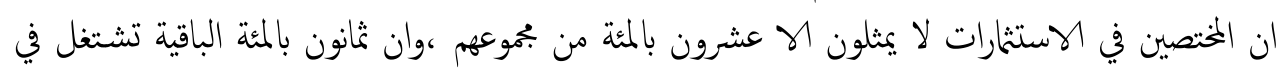

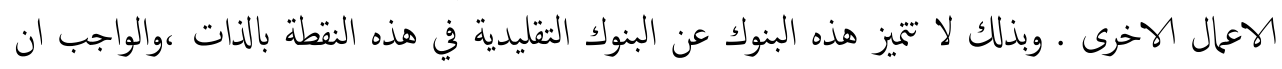

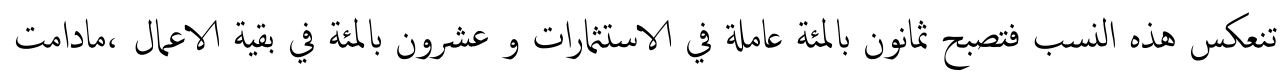

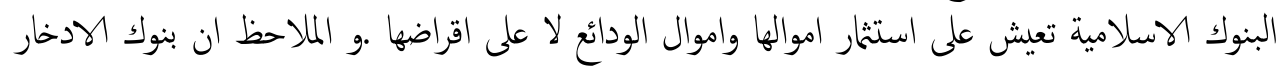

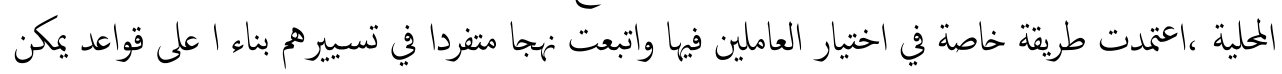
حصرها في النقاط التالية

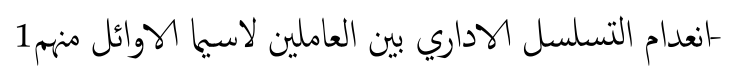

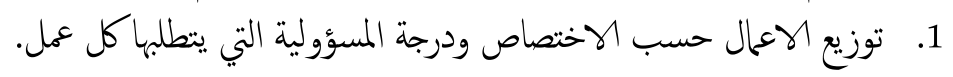

2.

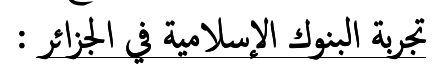
.III

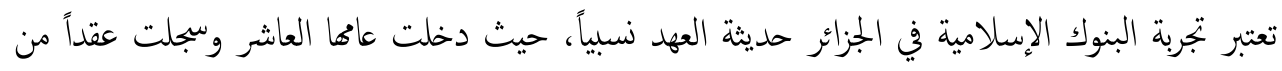

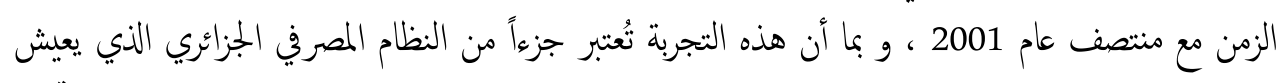

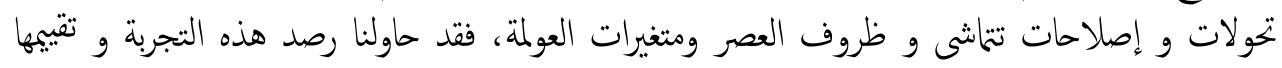

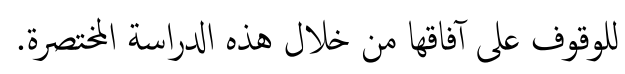

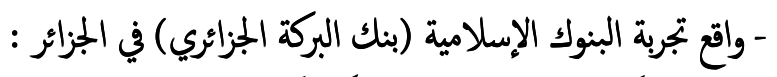

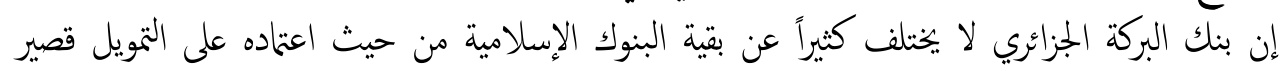

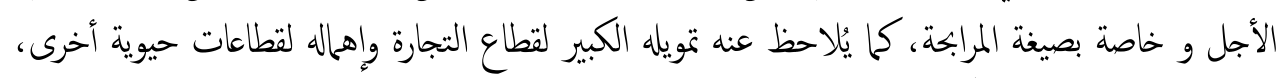

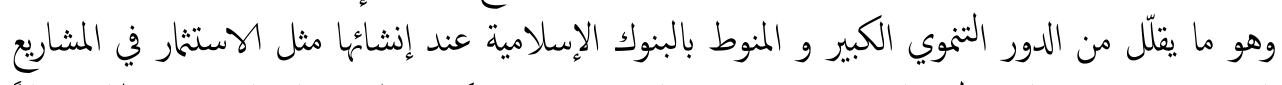

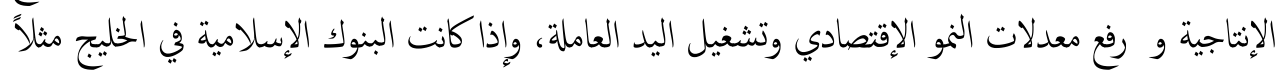

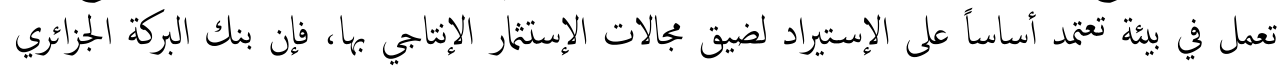




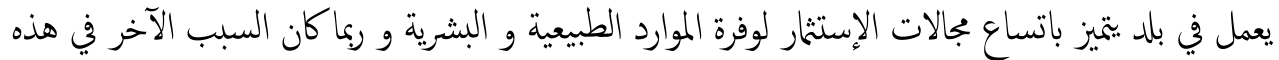

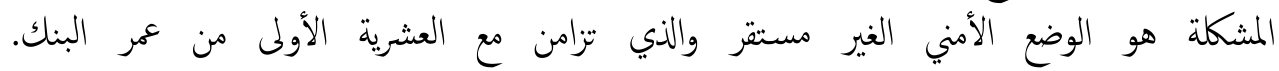

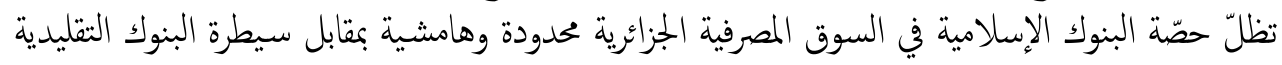

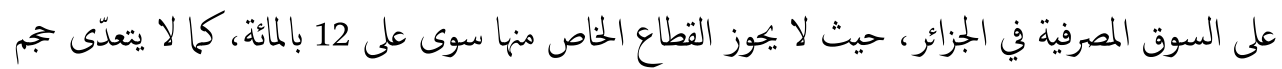

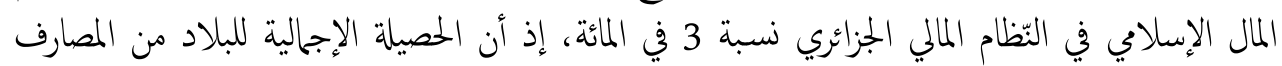

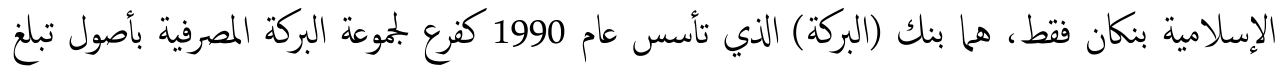

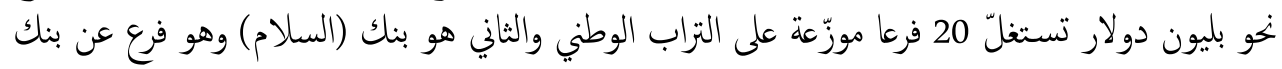

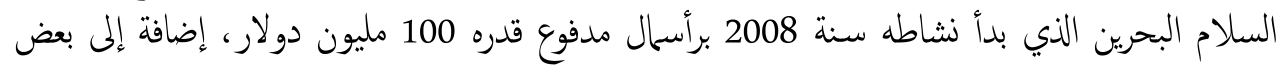

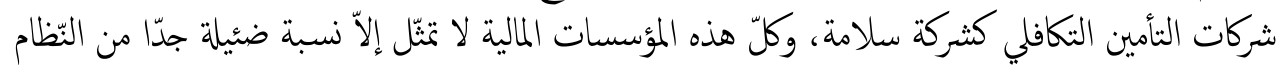

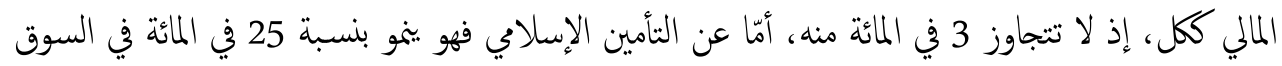

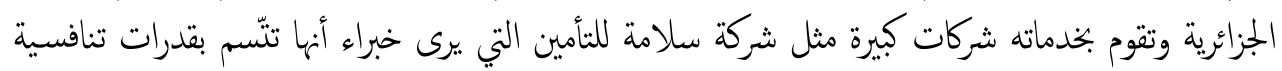

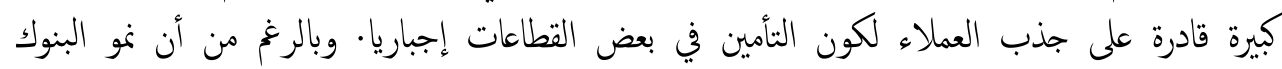

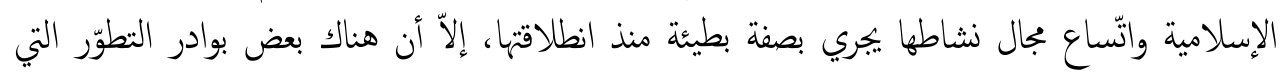

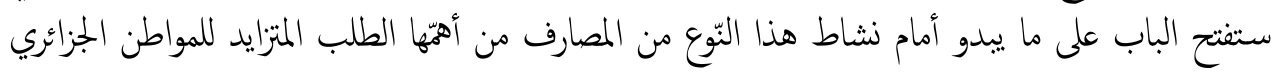
على الخدمات

تسيير الموارد البثرية في البنوك الإسلامية الجزائرية:

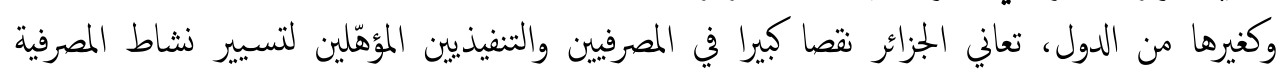
IV

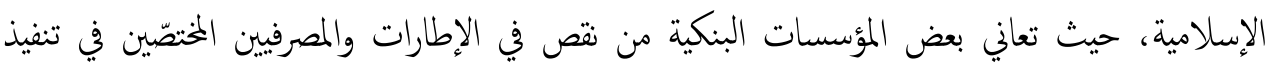

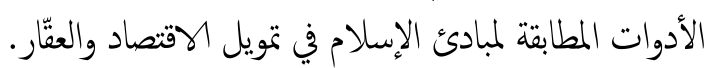

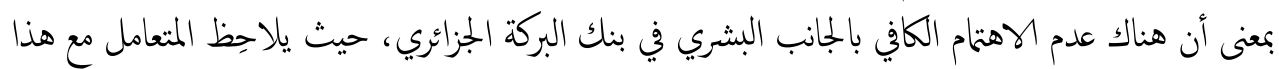

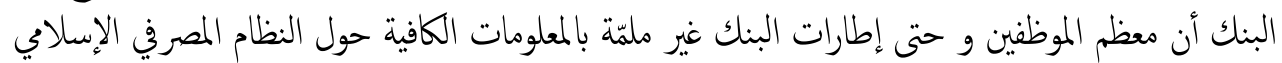

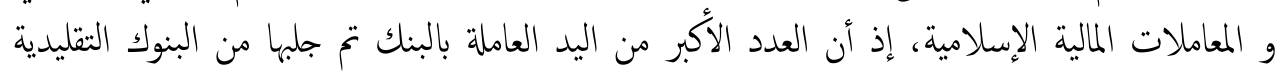

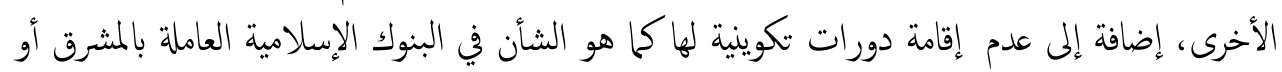

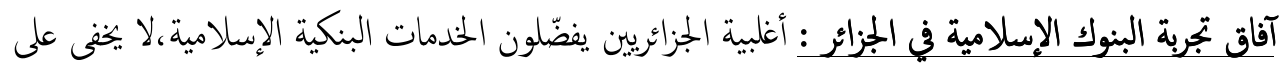
. $\mathrm{VI}$

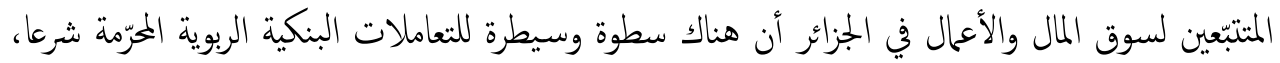

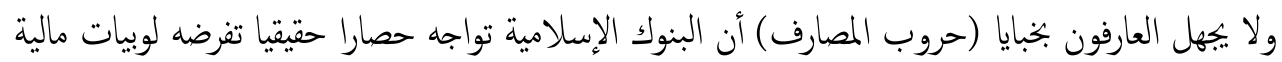

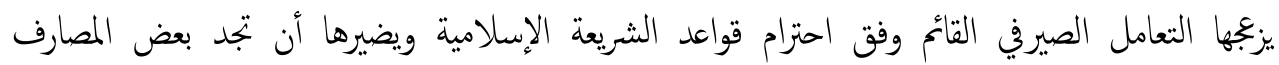

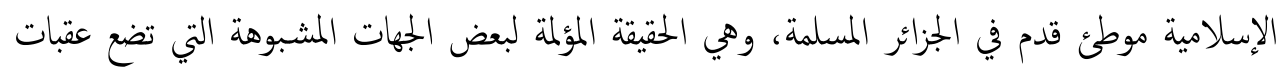
كثيرة أمام البنوك الإسلامية، إذ تشير بعض المئر المصادر إلى أن عددا من البنوك الخاصّة التي ينوي أصحابها 
إطلاقها ضمن حدود أحكام الدين الإسلاي مازالت تنتظر الضوء الأخضر للنشاط، وأن لوبيات بنكية

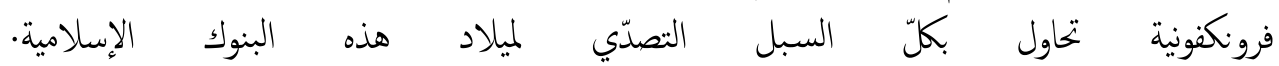
في مجال تسيير مواردها البشرية

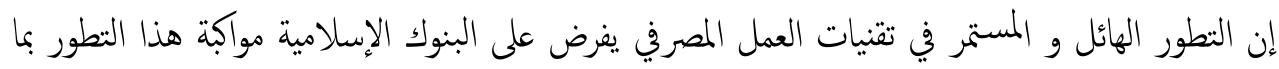

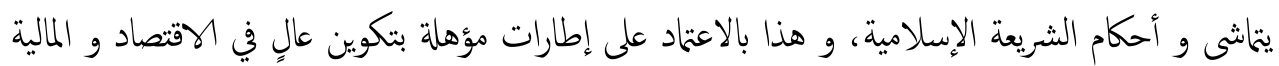

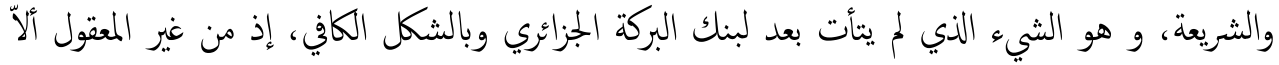

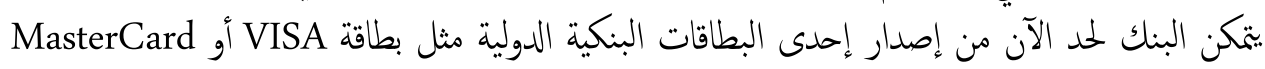

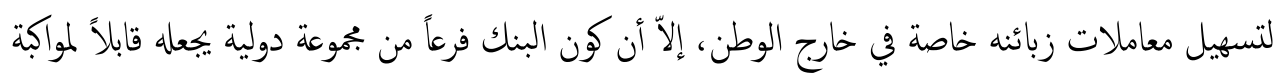
الكثير من التطورات مستقبلاً. خامتّة:

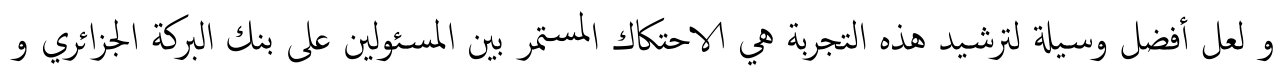

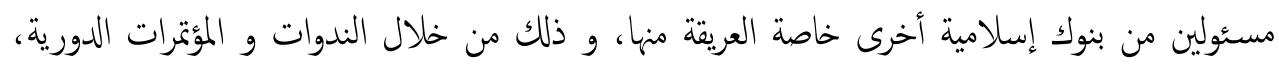

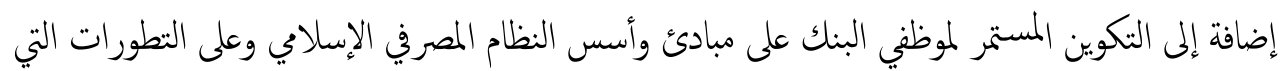

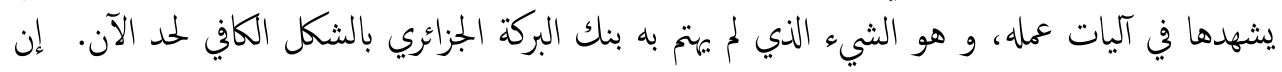

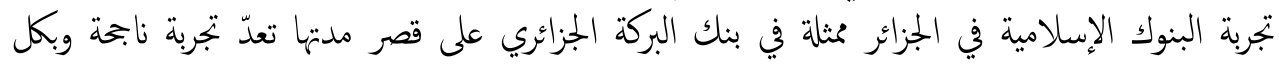

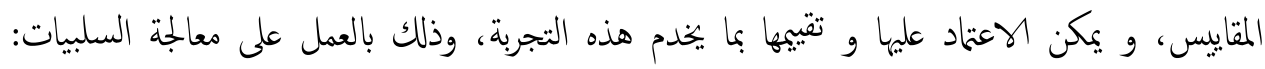

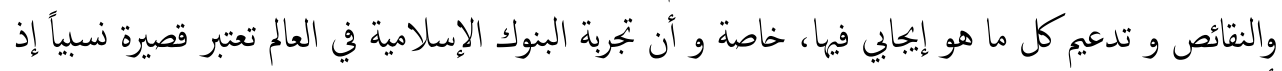

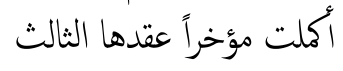
هنـالك بعض المقترحات المسـاعدة التي يككن ان تقوم بها المؤسسـة في مجال تسيير مواردهـا البشرية مثل :

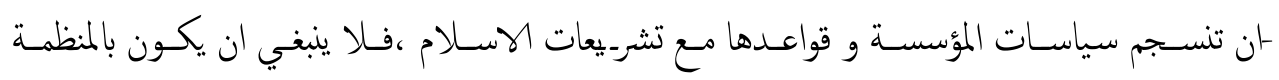

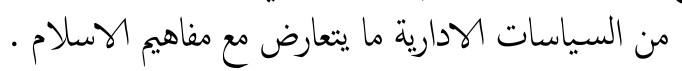

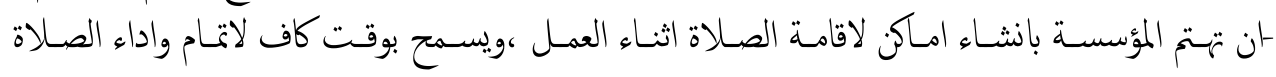

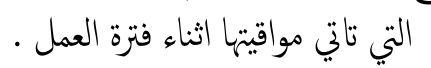

- ان يراعى عند انتقاء الافراد للعمل التاكد من سلامة اتجاهاتهم الدينية قبل اتخاد قرار تعيبيهم .

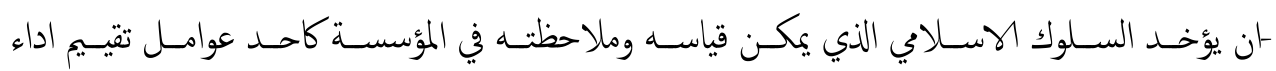

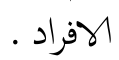

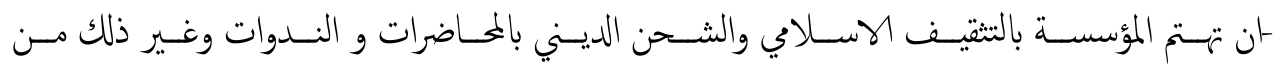

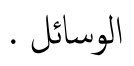




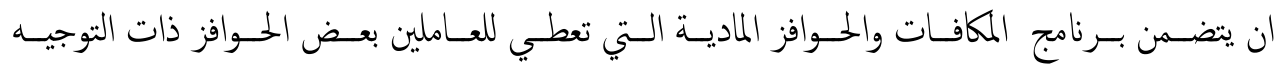
· الديني

ان تحرص المؤسسة على اقامة العدل في الاجور و المكافات وغير ذلك من الحوافز .

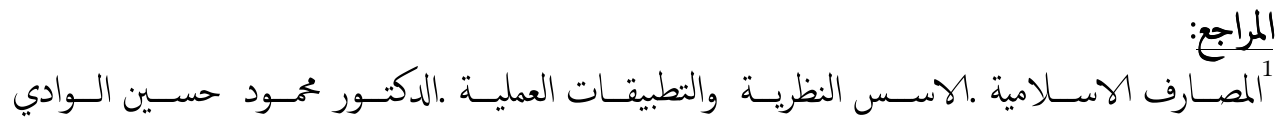

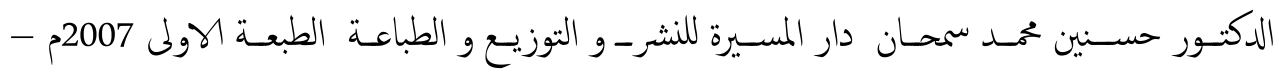
عمان الاردن

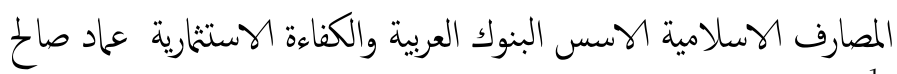

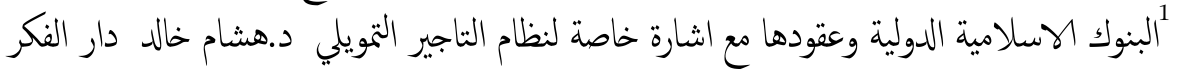
الجامعي 12007 الاكسكندرية بيروت لبنان -البنوك العربية و الكفاءة الهستثارية د.عهاد صالح سلام اتحاد المصارف العربية 2004

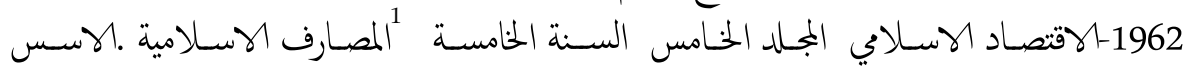

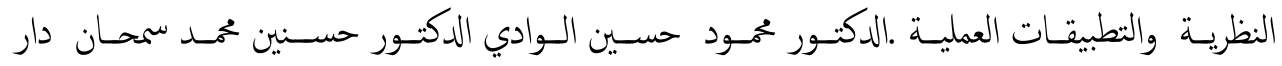

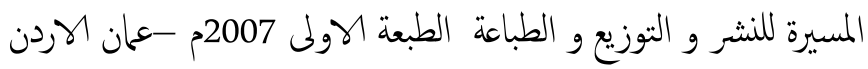

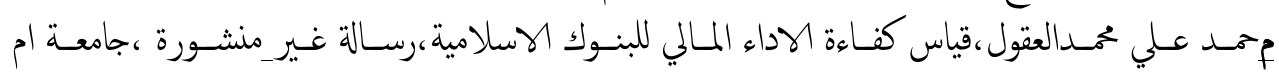
درمان الاسلامية، السودان 1997 إلكفــاءة التشـفيلية للمصـارف الاسـلامية -دراسـة تطبيقيـة مقارنـة-الدكتـور شـوقي بورقبـة دار النقـاش للنشر والتوزيع2013

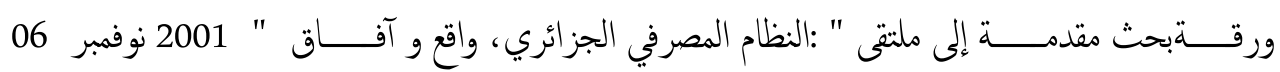
قالمة 05 - 05

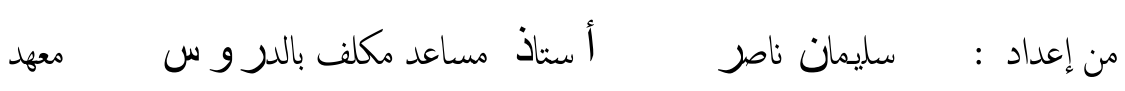

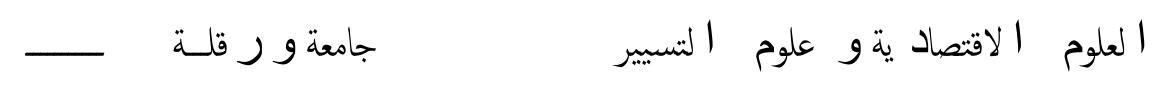

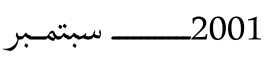
العمل المصرفي الإسلامي في الجزائر الواقع و الآفاق دراسة تقييمية مختصرة 